\section{In Search Of The Lost Cord: Solving the Mystery of Spinal Cord Regeneration}

by Luba Vikhanski

National Academy Press, 269 pp,

\$27.95 ISBN: 0309074371, 2001

\section{REVIEWED BY JEFFREY L. GOLDBERG Department of Neurobiology \\ Stanford University Medical School \\ Stanford, Califomia, USA}

Here is a twist on scientific storytelling: take a major clinical problem that everyone recognizes, and tell a gripping tale of the race for a solution before the problem is solvedl With no need to focus on the 'winning' scientist or therapy, all research seems rich with potential and every scientist is one step from gold. In Search of The Lost Cord exploits this method to detail the hunt for the secret of spinal cord regeneration. In writing it, Luba Vikhanski interviewed 150 scientists and cliniclans working on spinal paralysis, and weaved their stories into a gripping 200-page cliffhanger that is enjoyable and informative for scientists, clinicians and the public alike.

Understanding why our brain and spinal cord fail to repair themselves after injury is a problem that has plagued physicians and scientists since pen was put to papyrus. An estimated two million people worldwide suffering from spinal cord injuries have permanent impairments in functions the rest of us take for granted-walking, bowel and bladder control, sensation and sexual activity, even breathing. But excitement is mounting that a cure will come, as over the past few decades scientists and clinicians have initiated hundreds of studies that suggest that regeneration research is not such a dead end after all.

Great history writes itself, and Part 1 vividly describes the history of spinal cord regeneration research in this past century. The first few players will be recognizable to those in the field as individuals who have played prominent roles by virtue of the questlons they have posed. Will neurons re-extend their axons after injury in the brain or spinal cord? Vikhanski re- counts Cajal's scientific scuffles with his "arch-enemy" Golgi cementing the neuron theory of the brain, and his fundamental subsequent observation that unlike peripheral nerves, spinal cord axons sprout a little but fall to regenerate beyond injured spinal cord tissue. Was this fallure a problem with the neurons or with the environment? Cajal's student Tello performed peripheral nerve transplants into the brain that showed neurons would regenerate at least short distances if given a favorable environment. Short distances-but isn't the spinal cord rather long? Seventy years later Aguayo improved the transplant concept to demonstrate that a favorable environment actually allowed long-distance regeneration of a small percentage of spinal cord axons. The $\mathbf{7 0}$ years between Tello and Aguayo and those since are filled with lively characters-many of whom are still at it today-and with important advances that have kept regeneration research alive. Vikhanski paints their "struggle against the impossible" in colorful detail.

The book's subtitle should not mislead readers into thinking that science has arrived at a solution. There is no cure for spinal injury as yet, although human trials are now beginning for a handful of the current new strategies. Rather, it is the scientist's love of a good mystery that Vikhanski relates in

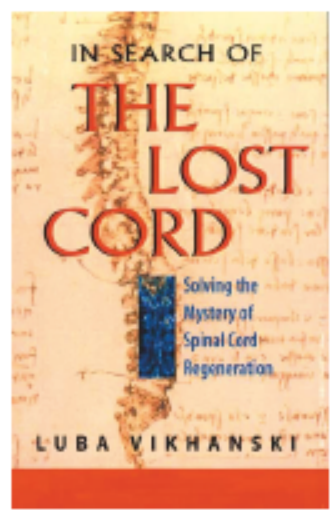

injured tissues electrically. The thread binding the chapters into a coherent whole is lost at times, and we could criticize this section for short-changing recent approaches stemming from genomics and proteomics that are exciting the scientific and clinical worlds. But there will always be one more line of attack as technology surges ahead, and these chapters do a good job of presenting how the mysteries drive the science forward in the hope of clinical benefit.

The Lost Cord is directed at the widest possible audience, and no one will waste an afternoon reading this book. Those in regeneration research will find the history in Part 1 most compelling but the ongoing research in Part 2 perhaps less so. Physicians and scientists in other fields who may be interested in the research and treatment strategies described in Part 2 will find the writing style slightly below their level of sophistication. Reference comments and sources are endnoted where they do not bog down the text, but they are not complete, and a number of unassigned quotations may bother the careful reader.

And for the general audience? The Lost Cord is characterized throughout by careful explanation without condescension. There is even an excellent appendix on spinal cord anatomy and function that is simple and clear for any reader.

Part 2. For example, how is the central nervous system different from the peripheral nervous system, which regenerates after injury? When our immune cells spill from the blood vessels into the site of a spinal cord injury, are they doing more harm than good? Why are axons guided in the right direction during development but not during adulthood? If our spinal cord 'learns' how to walk when we are babies, why does it not 're-learn' after an injury? These chapters whirl the reader through investigations arising from such questions: studies on coaxing the immune system into line; the science of reversing axon guidance mechanisms that may block regeneration in the adult; and research on novel therapies with stem cells and neural prostheses, which are neuro-silicon interfaces that bridge
Indeed, Vikhanski should be recruited to interview 150 scientists in another developing field, as the scientific world is well served by such an easy to read communication of the scientific process. The book is a window into how scientists formulate questions and share results, assailing the problem of spinal paralysis from many directions. In this respect, The Lost Cord is both educational and captivating.

Ultimately, though, can you enjoy a story without a happy ending? Hollywood may say no, but I say yes. A 3,500-year old Egyptian papyrus referred to spinal cord injury as a "disease that cannot be treated," and in large part this holds true today. But tomorrow? We'll reserve one more chapter for Vikhanski to add when tomorrow finally comes. 